Lisbon - Malacca Port Cities Twin Conferences 2019 / 2020

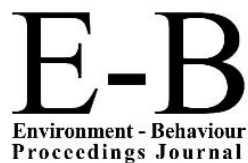

$$
\text { AicQoL2020Malacca }
$$

ASLI (Annual Serial Landmark International) Conferences on QoL2020

https://www.amerabra.org; https://fspu.uitm.edu.my/cebs; https://www.emasemasresources.com/

8th AMER International Conference on Quality of Life Mahkota Hotel Melaka, Malacca, Malaysia, 18-19 Mar 2020

(Due to the Covid-19 lockdown, paper virtually presented on 25 Mar 2020)

\title{
Developing a Questionnaire on Autistic Learning Environment
}

\author{
Roslinda Ghazali', Siti Rasidah Md Sakip 2, Ismail Samsuddin ${ }^{3}$ \\ 1 Department of Post-graduate, \\ 2 Department of Landscape Architecture, \\ 3 Department of Architecture, \\ Universiti Teknologi MARA, Perak, Malaysia \\ ${ }^{2}$ Green Safe Cities Research Group, \\ Universiti Teknologi MARA, Shah Alam, Selangor, Malaysia. \\ lindakeruing@gmail.com, sitir704@perak.uitm.edu.my, ismai578@perak.uitm.edu.my \\ Tel: 0135185148
}

\begin{abstract}
Developing a new questionnaire as a tool used in data collection might be the greatest challenge. The survey must be both valid and reliable. The purpose of the paper is to describe the processes undertaken to develop the questionnaire to measure awareness and knowledge among who involves in the autistic learning environment. The researcher refers to the expertise to check the quality of the tool. Each expert independently evaluated all details regarding the relevance, the clarity, and the understandability of the instrument. The overall content of the questionnaire comprises of sensory stimulation, sensory sensitivity, sensory design, and physical learning environment.
\end{abstract}

Keywords: Autism, pre-testing, questionnaire;

eISSN: 2398-4287 @ 2020. The Authors. Published for AMER ABRA cE-Bs by e-International Publishing House, Ltd., UK. This is an open access article under the CC BYNC-ND license (http://creativecommons.org/licenses/by-nc-nd/4.0). Peer-review under responsibility of AMER (Association of Malaysian Environment-Behaviour Researchers), ABRA (Association of Behavioural Researchers on Asians) and cE-Bs (Centre for Environment-Behaviour Studies), Faculty of Architecture, Planning \& Surveying, Universiti Teknologi MARA, Malaysia.

DOI: https://doi.org/10.21834/e-bpj.v5i13.1722

\subsection{Introduction}

The Centers for Disease Control and Prevention reported that autism is a developmental disability that can create social, communication, and behavioural challenges (Schaffhauser, 2018). Autism Spectrum Disorder (ASD) is a broad term used to refer to a set of developmental disabilities with similar core symptoms (Reynolds, 2015). Children with ASD can have a variety of abilities and impairments, and each child is affected differently. Research done by M. Kanakri (2017) indicated that the environment is essential to the treatment of autism because it influenced behaviour and suggested that architects and designers should modify the setting for this particular community. Failure to apply the precise environment which will reflect negatively on the development of an autistic child's behaviour (Hosny \& Anous, 2015). An autistic child may appear to behave unusually, and they can meltdown when they are in stressful situations. Therefore, architects and designers suggested providing an appropriate environment and design that responds to the needs of all members of society, especially for autistic children. However, designers are lack in terms of sensory issues regarding the built environment in the daily life of autism before the designing stage, especially in terms of the physical learning environment. This research objective is to develop the questionnaire to measure awareness and knowledge among who involves in the autistic learning environment. While the study aimed to describe the processes undertaken in the development and testing of questionnaires used for data collection. Before distributing a survey, the researcher refers to the expertise to check the quality of the tool. Each expert independently evaluated all details regarding the relevance, the clarity, and the understandability of the questionnaire. The pre-test of a research instrument 
involves a critical examination of each question as to its clarity, understanding, wording, and meaning as understood by potential respondents to remove possible problems with the issue.

\subsection{Background}

The overall content of the questionnaire comprises of sensory stimulation (lighting, smell, colour and visual). The sensory sensitivity (sight, sound, smell, taste, touch, proprioception, vestibular). The sensory design (acoustic, compartmentation, spatial sequencing, thresholds, escape space, sensory zoning, safety, and security). Finally, the physical learning environment (accessible, wayfinding, scale, toilet accommodation, ventilation, window, quiet room, legibility, and furniture).

\subsection{Methodology}

The process of developing a questionnaire involved a thorough understanding of the problem through a literature search. A review of the literature is carried out in this research to develop a broad understanding of sensory issues. Using this understanding, variables that significantly affect the autism identified. This 'quantitative approach' allows the data to be structured, evaluated, and analyzing data using SPSS and EXCEL. This approach will contribute to determining the 'knowledge' and 'awareness' of the participants towards the idea of creating a conducive physical learning environment for the autistic. Therefore, to develop a new questionnaire, many issues should be considered even before writing the questionnaire items.

\subsection{Identify the Key Concept}

The process to construct the survey for the study mostly derives from Environment-Behavior research methods discussed by (Khare \& Mullick, 2008). Related to the objective of this research is to develop the questionnaire to measure awareness and knowledge among who involves in the autistic learning environment. The key concept captured from the previous study derives from available literature the sensory sensitivity and sensory stimulation (Hebert, 2003; Beaver, 2006; Liss Radunovich \& Kochert, 2014; Gaines, Bourne, Pearson, \& Kleibrink, 2016; Gaines et al., 2016). While the existing theories of sensory design and physical learning environment for autism (Fraser, 1994; Paron-Wildes, 2005; Kilgour 2006; Society, 2015, Mostafa, 2015, Shaari \& Ahmad, 2016). The key concept also creates from the researcher's experiences during the preliminary study and the extensive literature on autism. The initial exploration carried out is to deepen the understanding of the concept.

\subsection{The Questionnaire Format}

The questionnaire designed to close-ended and self-administered by the respondent. It is hoped that respondents may be more likely to respond truthfully if they are allowed to complete the survey on their own. This format is more comfortable to administer and analyze. Therefore, the items need to written in a way that can be easily understood by the majority of the respondents (Tsang, Royse, \& Terkawi, 2019).

\subsection{The Length of Questionnaire}

The questionnaire designed to measure the necessary items. The questions should not be so long that respondents experience fatigue or loss of motivation in completing the survey (Tsang et al., 2019). They also suggested that those questions not only should a survey keep the simplest structure, but it also should consist of items that adequately represent the construct of interest to minimize measurement error. Tsang et al., (2019) mentioned that although a simple structure of questionnaire recommended, a large item needed in the early stages of the questionnaire's development as many of these items discarded throughout the development process.

\subsection{Measure}

The researcher constructs the questionnaire referring to key concept. There are Sensory Sensitivity consists of sight, sound, smell, touch, taste, proprioception and vestibular. Sensory Stimulation consists of acoustic, colour, smell, lighting and visual. The Sensory Design consists of the seven design criteria such as acoustics, spatial sequencing, escape space, compartmentalization, transition spaces, sensory zoning, and safety. The physical learning environment consists of building scale, accessibility, wayfinding, toilet provision, window, ventilation and heating, threshold, legibility, and furniture. The questionnaire consists of seven (7) sections with a total of one hundred and forty-four (149) questions tabulated, as shown below.

Table 1. A Sectional Questionnaire Survey

\begin{tabular}{|c|c|}
\hline Information Sheet & $\begin{array}{l}\text { This section is essential for the respondent to read and understand why the research is done } \\
\text { and what it will involve }\end{array}$ \\
\hline Instruction for rating measure & 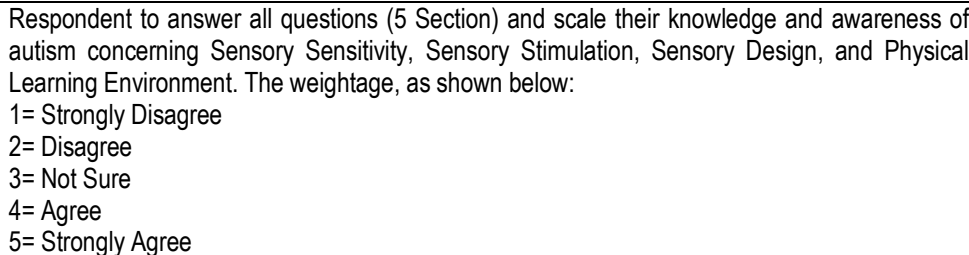 \\
\hline
\end{tabular}




\begin{tabular}{|c|c|}
\hline Section 1 & Demographic Data - Respondent's background \\
\hline Section 2 & $\begin{array}{cl}\text { Sensory } & \text { Sensitivity (SSy) - (30 questions) } \\
\text { - } & \text { Sight (5 questions) } \\
\text { - } & \text { Sound (5 questions) } \\
\text { - } & \text { Smell (5 questions) } \\
\text { - } & \text { Taste (5 questions) } \\
\text { - } & \text { Proprioception (5 questions) } \\
\text { - } & \text { Vestibular (5 questions) } \\
\end{array}$ \\
\hline Section 3 & $\begin{array}{cl}\text { Sensory Stimulation (SSn) - (27 questions) } \\
\text { - } & \text { Acoustic (5 questions) } \\
\text { - } & \text { Colour (7 questions) } \\
\text { - } & \text { Smell (5 questions) } \\
\text { - } & \text { Lighting (5 questions) } \\
\text { - } & \text { Visual (5 questions) } \\
\end{array}$ \\
\hline Section 4 & $\begin{array}{cl}\text { Sensory Design (SD) - (35 questions) } \\
\text { - } & \text { Acoustic (6 questions) } \\
\text { - } & \text { Spatial sequencing (5 questions) } \\
\text { - } & \text { Escape space (5 questions) } \\
\text { - } & \text { Compartmentation (5 questions) } \\
\text { - } & \text { Transition zone (5 questions) } \\
\text { - } & \text { Sensory zoning (5 questions) } \\
\text { - } & \text { Safety and security (6 questions) } \\
\end{array}$ \\
\hline Section 5 & $\begin{array}{cl}\text { Physical Learning Environment (PLE) - (45 questions) } \\
\text { - } \quad \text { Building scale (5 questions) } \\
\text { - } \quad \text { Accessibility (5 questions) } \\
\text { - } \quad \text { Tayfinding (5 questions) } \\
\text { - } \quad \text { Window (5 questions) } \\
\text { - } \quad \text { Ventilation and heating (5 questions) } \\
\text { - } \quad \text { Threshold (5 questions) } \\
\text { - } \quad \text { Legibility (5 questions) } \\
\text { - } \quad \text { Furniture (5 questions) }\end{array}$ \\
\hline
\end{tabular}

\subsection{Review Questionnaire}

Appointed expert $(n=9)$ were selected based on their knowledge and expertise to review a questionnaire. The researcher invited them to participate and assess the 149 items in the survey. The questionnaire sent to experts in various disciplines with a request for feedback on the relevance, clarity and understandability of each item. The experts were also asked to comment and suggestion if certain components were missing. The expert was contacted by email. This is important to ascertain whether the content of the questionnaire was appropriate and relevant to the study purpose. The level of clarity for each item and the level of understandability on a Likert scale of 1-4, as shown below:

The appointed experts reviewed the items to make sure they are accurate, free of item construction problems, and grammatically correct. The expert at their ability ensures that the items do not contain content that may be perceived as offensive or biased by a particular subgroup of respondents (Tsang et al., 2019). Development and testing through an expert usually undertaken by seven or more experts (Parsian, 2019). This research was undertaken by a professional architect, expert panels and related field research as shown below:

Table 2. The Rating Measure for Expert

\begin{tabular}{lll}
\hline \multicolumn{1}{c}{ Relevance } & \multicolumn{1}{c}{ Clarity } & Understandability \\
\hline $1=$ not relevance & $1=$ Item is not clear & 1= Item is not understandable \\
\hline $2=$ somewhat relevance & $2=$ Item needs major revision to be clear & $2=$ Item needs major revision to be clear \\
\hline $3=$ relevance & $3=$ Item needs minor revision to be clear & $3=$ Item needs minor revision to be clear \\
\hline $4=$ very relevance & $4=$ Item is clear $\quad 4=$ Item is clear \\
& & \\
& & (Source: Author)
\end{tabular}


Table 3. List of Experts

\begin{tabular}{|c|l|l|}
\hline Expert & \multicolumn{1}{|c|}{ Profession } & \multicolumn{1}{|c|}{ Working Experience } \\
\hline Expert 1 & Occupational Therapies & More than 15 year's \\
\hline Expert 2 & Interventionist & Less than five year's \\
\hline Expert 3 & Biostatistician \& Research methodologist & $6-10$ year's \\
\hline Expert 4 & $\begin{array}{l}\text { Professional Architect } \\
\text { (Designer Stage) }\end{array}$ & More than 15 year's \\
\hline Expert 5 & $\begin{array}{l}\text { Professional Architect } \\
\text { (Experiencing autism) }\end{array}$ & More than 15 year's \\
\hline Expert 6 & $\begin{array}{l}\text { Professional Architect } \\
\text { (Construction Stage) }\end{array}$ & More than 15 year's \\
\hline Expert 7 & Academician & $11-15$ year's \\
\hline Expert 8 & $\begin{array}{l}\text { Occupational Therapist (Saudi Arabia) } \\
\text { (Certified Therapist in Sensory Integration Therapy) }\end{array}$ & More than 15 year's \\
\hline Expert 9 & Special Education Educator & More than 15 year's \\
\hline
\end{tabular}

(Source: Author)

\subsection{Pre-Testing Instrument}

In quantitative research, pre-testing is a practice whereby researchers would test the research instrument that has been developed before its actual use to ascertain the likely problems with it (Kothari, Kumar, \& Uusitalo, 2014). A pre-test should be carried out under actual field conditions on a group of people similar to the research population. The purpose is not to collect data but to identify problems that the potential respondents might have in either understanding or interpreting a question. The researcher is to determine if there are problems in understanding the way a question has worded, the appropriateness of the meaning it communicates, whether different respondents interpret a question differently, and to establish whether their interpretation is different from what you were trying to convey. If there are problems, need to re-examine the wording to make it more precise and unambiguous (Kothari et al., 2014).

\subsection{Procedures}

The ethical issues considered to maintain the participants' confidentiality and privacy in the research conducted. The ethical permission obtained from the administration of the Public Works Department Malaysia and National Medical Research to undergo research in the Jabatan Kerja Raya Malaysia and Genius Kurnia. The participants will be given a set of questionnaires and inform consent to explain briefly the nature of the study to enable the participants to decide on taking part in the survey. The autonomy of the participants also emphasized in the consent. Data will be collected through a questionnaire distributed to those who involve in the autistic learning environment and architects who participate with autism project. The participant must answer and respond to all questions on the questionnaire. The completed survey will be collected from the participants, and finally, all the information about the participant is kept confidential.

\subsection{Limitation}

The scope of study involves early intervention classrooms at the age of four to six years old in Genius Kurnia that facilitated by the government. The researcher could not get approval at the initial stage from the Autism Centre before conducting preliminaries study. Therefore, the observation was done away from the children and only visiting an empty room without autistic children. During the preliminary research, the researcher was also advised by the interventionist not to close to autistic children. This task is a challenge for her to observe the existing environment with the children occupied in the classroom. There is a limitation to approach an expert to validate the questionnaire. The selected expert did not respond and not interested in taking part in this validation phase. Moreover, the researcher has to wait for a long time for an expert to respond from reviewing the questionnaire. There are not many experts in this field, therefore researcher approach expert from oversea to review and feedback the survey.

\subsection{Findings}

The pre-test of a research instrument entails a critical examination of each question as to its clarity, understanding, wording, and meaning as understood by potential respondents to remove possible problems with the question. It ensures that a respondent's understanding of each question is by researcher intentions (Kothari et al., 2014). After the pre-test, further alterations made to the questionnaire. The overall comments from experts suggested that some question is not relevant to ask, reconsider to minimize those questions, to modify into a more proper sentence, to modify question shorter and use more positive statement. Other comments on some sentences are not understandable and unclear. It recommended that independently administered (self-completion) questionnaires are short in length and are composed mostly of closed structure questions (Mackison, Wrieden, \& Anderson, 2010). Therefore, the researcher revised, strengthen the survey, send for proofreading and modified accordingly based on those comments and suggestions by the experts.

\subsection{Discussion and Conclusion}

This paper, we provided processes on how to develop a new questionnaire for the respondents about their knowledge and awareness regarding the autism environment. In the development of this instrument, the researcher involved an extensive literature search, reviewing the findings from existing literature and highlighting any gaps in the current research. The review highlighted the limited availability of studies reporting the development of an instrument to measure an architect's knowledge and awareness towards the 
autism environment. In the development of this instrument, the important is the readability level of the questionnaire. The researcher must be careful to avoid long sentences, complex terminology, acronyms or abbreviations, double-barreled, and leading questions.

Researchers emphasized the major phases that need to be undertaken when constructing a new questionnaire. The questionnaire items should be able to relate to the theoretical construct as intended clearly. Tsang et al., (2019) explained that although such associations may be obvious to researchers who are familiar with the specific topic, they may not be apparent to other readers and reviewers. They also suggested that to develop a good questionnaire that can subsequently be applied in research, and it is crucial to invest the time and effort to ensure that the items adequately assess the construct of interest.

The development of the questionnaire for data collection is important to reduce measurement errors. The process to develop questionnaire should consider thorough on the content, design and format. Researchers entirely give attention to the understanding of the process involved in developing a survey. Not following appropriate and systematic procedures in questionnaire development, testing, and evaluation may challenge the quality and utilization of data (Radhakrishna, 2007). Although developing a questionnaire is not an easy task, the processes outlined in this paper should enable researchers to end up with surveys that are effective in the target populations during data collection.

\section{Acknowledgements}

I would like to thank my supervisor Dr Siti Rasidah Md Sakip and Asso. Prof. Dr Ismail Samsuddin for supporting me. Also, I would thank Jabatan Kerja Raya Malaysia for allowing me to further my study.

\section{References}

Beaver, C. (2006). Designing Environments for Children \& Adults with ASD. In Autism Safari 2006 2nd World Autism Congress \& Exhibition.

Gaines, K., Bourne, A., Pearson, M., \& Kleibrink, M. (2016). Designing for Autism Spectrum Disorders. https://doi.org/10.4324/9781315856872

Hebert, B. B. (2003). Design Guidelines of a Therapeutic Garden for Autistic Children. Louisiana State University.

Hosny, I., \& Anous, I. (2015). The impact of Interior Design in educational spaces for children with Autism. 90-101.

Khare, R., \& Mullick, A. (2008). Educational Spaces for Children with Autism; Design Development Process. Building Comfortable and Liveable Environments for All : International Meeting Education And Training, Georgia Tech University, Atlanta, USA., (May), 66-75.

Kothari, C., Kumar, R., \& Uusitalo, O. (2014). Research Methodology. In New Age International. https://doi.org/http://196.29.172.66:8080/jspui/bitstream/123456789/2574/1/Research\%20Methodology.pdf

Liss Radunovich, H., \& Kochert, J. L. (2014). Creating a Successful Early Learning Environment for Children Who Have Autism Spectrum Disorders 1 What Are Autism Spectrum Disorders? IFAS Extension, 1-6.

M. Kanakri, S. (2017). Spaces Matters: Classroom Acoustics and Repetitive Behaviors in Preschool Children with Autism. American Journal of Pediatrics, 3(6), 89. https://doi.org/10.11648/j.ajp.20170306.15

MacKison, D., Wrieden, W. L., \& Anderson, A. S. (2010). Validity and reliability testing of a short questionnaire developed to assess consumers use, understanding and perception of food labels. European Journal of Clinical Nutrition, 64(2), 210-217. https://doi.org/10.1038/ejcn.2009.126

Mostafa, M. (2015). An Architecture for Autism: Built Environment Performance in Accordance to the Autism ASPECTSSTM Design Index. Design Principles and Practices: An International Journal-Annual Review, 8(1), 55-71. https://doi.org/10.18848/1833-1874/CGP/v08/38300

Paron-Wildes, A. J. (2005). Sensory Stimulation and Autistic Children. Implications, 06(04), 1-5.

Parsian, N. (2019). Developing and validating a questionnaire to measure women's sexual behaviors: A psychometric process. Global Journal of Health Science, 1(1), 208-214.

Radhakrishna, R. B. (2007). Tips for Developing and Testing Questionnaires / Instrumen Step 1--Background Step 2--Questionnaire Conceptualization. Journal of Extension, 45(1), Online. Retrieved from http://www.joe.org/joe/2007february/tt2.php

Reynolds, J. D. (2015). A View of Parents of Children with Autism Spectrum Disorder. Liberty University.

Schaffhauser, D. (2018). Sensory Room Provides Focus for Autistic Students. THE Journal -Special Needs. Retrieved from file://IC:/Users/User/Dropbox/ORGANIZER/AUTISM/sensory design/Sensory Room Provi des Focus for Autistic Students -- THE Journal.html

Shaari, M. F., \& Ahmad, S. S. (2016). Physical Learning Environment: Impact on Children School Readiness in Malaysian Preschools. Procedia - Social and Behavioral Sciences, 222, 9-18. https://doi.org/10.1016/j.sbspro.2016.05.164

Society, T. N. A. (2015). Autism Friendly Design. Your Autism Magazine, 49(2), 513600-513600. Retrieved from http://www.autism.org.uk/professionals/others/architects/autism-friendly-design.aspx

Tsang, S., Royse, C. F., \& Terkawi, A. S. (2019). Guidelines for developing, translating , and validating a questionnaire in perioperative and pain medicine. 11(Suppl 1), 1-15. https://doi.org/10.4103/sja.SJA 